\title{
Hygiene-therapists could be used to screen for dental caries and periodontal disease
}

\author{
Abstracted from \\ Macey R, Glenny A, Walsh T, Tickle M, Worthington H, Ashley J, Brocklehurst P. \\ The efficacy of screening for common dental diseases by hygiene-therapists: \\ a diagnostic test accuracy study. I Dent Res 2015; 94: 70S-78S. \\ doi: 10.1177/0022034514567335. Epub 2015 Jan 20. PubMed PMID: 25604256. \\ Address for correspondence: Richard Macey, School of Dentistry, University of Manchester, \\ Oxford Road, Manchester, UK. E-mail: richard.macey@manchester.ac.uk
}

\section{Question: Can dental hygiene-therapists screen for caries and periodontal disease?}

Methodology A purposive sample of large NHS dental practices with a minimum of three surgeries employing at least one hygienetherapist (HT) was taken. Asymptomatic patients attending for routine checkups who consented to the study underwent a screen by $\mathrm{H}-\mathrm{T}$ for dental caries and periodontal disease (index test) followed by a screen by a general dental practitioner (reference test). Patients were recruited consecutively. $\mathrm{H}$-Ts and dentists attended a compulsory training day, which covered recruitment, consenting, screening process, calibration using stock photographs and patient record form completion. Diagnostic threshold for caries was any tooth in the patient's mouth that showed evidence of frank cavitation or shadowing and opacity that would indicate dental caries into the dentine. The diagnostic threshold for periodontal disease was any pocket in the patient's mouth where the blackband of a basic periodontal examination (BPE) probe (3.5 to 5.5 $\mathrm{mm}$ ) partially or totally disappeared (ie BPE code 3 ). The index test was compared with the reference test to determine true-positive, false-positive, false-negative and true-negative values. Sensitivity, specificity, positive predictive value, negative predictive value and diagnostic odds ratios are shown in table 1.

Results Eighteen hundred and ninety-nine patients consented to dental screening with 996 patients being randomly allocated to see the dentist first and $903 \mathrm{H}-\mathrm{T}$ first. The time interval between the index and reference test never exceeded 21 minutes. With the exception of two practices failing to collect data on smoking and dentures there were no missing results regarding the outcome of a positive or negative screening decision. No adverse events were reported. Mean screening time was five min $25 \mathrm{~s}$ for $\mathrm{H}$-Ts and four min $26 \mathrm{~s}$ for dentists. Dentists identified 668 patients with caries (Prevalence of

Table 1. Summary Sensitivity and Specificity points and Diagnostic Odds Ratios

\begin{tabular}{l|l|l|l|} 
& $\begin{array}{l}\text { Sensitivity } \\
\text { Summary point } \\
(95 \% \mathrm{Cl})\end{array}$ & $\begin{array}{l}\text { Specificity } \\
\text { Summary point } \\
(95 \% \mathrm{Cl})\end{array}$ & $\begin{array}{l}\text { Diagnostic } \\
\text { Odds Ratio } \\
(95 \% \mathrm{Cl})\end{array}$ \\
\hline Caries & $\begin{array}{l}0.81 \\
(0.74 \text { to } 0.87)\end{array}$ & $\begin{array}{l}0.87 \\
(0.78 \text { to } 0.92)\end{array}$ & $\begin{array}{l}28.10 \\
(15.5 \text { to } 50.95)\end{array}$ \\
\hline $\begin{array}{l}\text { Periodontal } \\
\text { Disease }\end{array}$ & $\begin{array}{l}0.89 \\
(0.86 \text { to } 0.92)\end{array}$ & $\begin{array}{l}0.75 \\
(0.66 \text { to } 0.82)\end{array}$ & $\begin{array}{l}24.99 \\
(14.59 \text { to } 42.82)\end{array}$
\end{tabular}

0.35) while $\mathrm{H}$-Ts classified 548 positive and correctly identified 1,047 of the 1,231 patients with no caries. Dentists identified 1074 patients with at least one pocket exceeding $3.5 \mathrm{~mm}$ in depth. Of these 935 were correctly identified by the H-Ts. For the 825 screened as negative by the dentist H-Ts correctly identified 621 .

Conclusions The results suggest that hygiene-therapists could be used to screen for dental caries and periodontal disease. This has important ramifications for service design in public-funded health systems.

\section{Commentary}

A significant proportion of activity in the NHS dental team in the UK related to the routine check-up, and a large number of patients do not require any further intervention. Traditionally the dentist, the most expensive member of the dental team, performs this role. The utilisation of other suitably trained members of the dental team to undertake some of this activity can be used to reduce delivery costs, improve efficiency and compensate for shortages. A number of reviews ${ }^{1-4}$ of this potential for role substitution have been undertaken, although most of the studies carried out to date in dentistry are old and of poor quality, as highlighted in the recent Cochrane review which concluded: 'We only identified five studies for inclusion in this review, all of which were at high risk of bias, and four were published more than 20 years ago, highlighting the paucity of high-quality evaluations of the relative effectiveness, cost-effectiveness and safety of dental auxiliaries compared with dentists in performing clinical tasks.'

Consequently it is good to see the publication of this well conducted study, which aimed to assess whether H-Ts could be used in a screening role for caries and periodontal disease in a general dental practice environment. The study methodology was designed to meet the Standards for Reporting of Diagnostic Accuracy (STARD), which has just recently been updated and is available on line http:// www.equator-network.org/reporting-guidelines/stard/. One of the main weaknesses in relation to STARD is that the practice dentists themselves were the gold or reference standard against which the H-Ts were measured, a point highlighted by the study authors. However, this pragmatic approach and the practice-based approach of this methodology strengthen its applicability to real-world UK general dental practice.

As no diagnostic procedure is $100 \%$ accurate the authors have also estimated the impact of false negative and false positive diagnoses for caries and periodontal disease in 100 patients where 35\% have caries and $57 \%$ have periodontal disease (Table 2). 
Table 2. Impact of calculated summary point sensitivity and specificity in 100 patients

\begin{tabular}{l|l|l|l} 
& $\begin{array}{l}\text { Disease } \\
\text { prevalence }\end{array}$ & $\begin{array}{l}\text { Undetected } \\
\text { by H-T } \\
\text { (False negative) }\end{array}$ & $\begin{array}{l}\text { Unnecessary } \\
\text { referral } \\
\text { (False positive) }\end{array}$ \\
\hline Caries & 0.35 & 7 patients & 8 patients \\
\hline $\begin{array}{l}\text { Periodontal } \\
\text { disease }\end{array}$ & 0.57 & 6 patients & 11 patients
\end{tabular}

The results from this study suggest that H-Ts would be able to screen for caries and periodontal disease. This supports the findings of the Galloway et al. review, which included 26 studies all considered to be low quality but providing a consensus that professionals complimentary to dentists with appropriate training can perform screening and diagnosis as well as dentists.

The authors also discuss the potential impact of this study on the NHS dental service in England, indicating that based on their findings an estimated 10 million of the 13 million adult dental examinations could in theory have been carried out by H-Ts. With increasing emphasis on the greater provision of preventions and more focus on reducing inequalities, increasing use of $\mathrm{H}$-Ts and the wider dental team could have a important influence on the way in which dental care is delivered in the future.

\section{Derek Richards}

Centre for Evidence-based Dentistry, Dental Health Services Unit, Dundee Dental Hospital and School, University of Dundee, Scotland, UK

1. Sibbald B, McBride A, Birch S. Labour substitution and efficiency in health care delivery: general principles and key messages. Centre for Workforce intelligence. London 2011. (Downloaded from http://www.cfwi.org.uk/publications/laboursubstitution-and-efficiency-in-healthcare-delivery-general-principles-and-keymessages) [Accessed 7 December 2015]

2. Dyer TA, Brocklehurst $P$, Glenny AM, et al. Dental auxiliaries for dental care traditionally provided by dentists. Cochrane Database Syst Rev 2014; 8: Art. No. CD010076. DOI: 10.1002/14651858.CD010076. pub2.

3. Wright JT, Graham F, Hayes C, et al. A systematic review of oral health outcomes produced by dental teams incorporating midlevel providers. J Am Dent Assoc 2013; 144: $75-91$.

4. Galloway I, Gorham I, Lambert M, et al. The Professionals' Complementary to Dentistry: A Systematic Review and Synthesis. London: University College London, Eastman Dental Hospital, Dental Team Studies Unit, 2003. Available to download at http://www.nationalelfservice.net/cms/wp-content/uploads/2013/01/PCD-Reviewcomplete.pdf [Accessed 7 December 2015]

Evidence-Based Dentistry (2015) 16, 116-117. doi:10.1038/sj.ebd.6401136 